\title{
Inhibition of interleukin 8/C-X-C chemokine receptor 1,/2 signaling reduces malignant features in human pancreatic cancer cells
}

\author{
SHENGLING FU ${ }^{1,2}$, XIANG CHEN ${ }^{2}$, HUEY-JEN LIN ${ }^{3}$ and JIAYUH LIN ${ }^{2}$ \\ ${ }^{1}$ Department of Thoracic Surgery, Tongji Hospital, Tongji Medical College, Huazhong University of Science and Technology, \\ Wuhan 430030, P.R. China; ${ }^{2}$ Department of Biochemistry and Molecular Biology, School of Medicine, \\ University of Maryland, Baltimore, MD 21201; ${ }^{3}$ Department of Medical Laboratory Sciences, \\ University of Delaware, Newark, DE 19716, USA
}

Received October 13, 2017; Accepted January 31, 2018

DOI: $10.3892 /$ ijo.2018.4389

\begin{abstract}
Interactions between interleukin (IL)-8 and its receptors, $\mathrm{C}-\mathrm{X}-\mathrm{C}$ chemokine receptor $1,(\mathrm{CXCR} 1)$ and CXCR2 serve crucial roles in increasing cancer progression. Inhibition of this signaling pathway has yielded promising results in a number of human cancers, including breast, melanoma and colon. However, the effects of CXCR $1 / 2$ antagonist treatment on pancreatic cancer remain unclear. The present study aimed to demonstrate that treatment with the clinical grade CXCR $1 / 2$ antagonist, reparixin, or the newly discovered CXCR1/2 antagonist, SCH527123, may result in a reduction of the malignant features associated with this lethal cancer. The effects of reparixin or SCH527123 exposure on human pancreatic cancer cell lines BxPC-3, HPAC, Capan-1, MIA $\mathrm{PaCa}-2$, and AsPC-1 were examined in regard to cell proliferation, cell viability, colony formation and migration. The effects of CXCR1/2 inhibition on the protein expression of well-known downstream effectors, including phosphorylated (p)-signal transducer and activator of transcription 3 (STAT3), p-RAC- $\alpha$ serine/threonine-protein kinase (p-AKT), p-extracellular signal-regulated kinase (p-ERK1/2) and p-ribosomal protein S6 (p-S6), were assessed by western blotting assays. The effects of IL-8 signaling on the proliferative activities intrinsic to the human pancreatic cancer cell lines Capan-1, AsPC-1 and HPAC were examined by bromodeoxyuridine assay. Treatment with either reparixin or SCH527123 yielded dose-dependent growth suppressive effects on HPAC, Capan-1 and AsPC-1 cells that may have otherwise undergone robust
\end{abstract}

Correspondence to: Professor Jiayuh Lin, Department of Biochemistry and Molecular Biology, School of Medicine, University of Maryland School of Medicine, 108 North Greene Street, Baltimore, MD 21201, USA

E-mail: jlin@som.umaryland.edu

Key words: interleukin 8, C-X-C chemokine receptor 1, C-X-C chemokine receptor 2, pancreatic cancer, reparixin, SCH527123 proliferation upon IL-8 stimulation. In addition, reparixin or SCH527123 treatment inhibited CXCR1/2-mediated signal transduction, as demonstrated by the decreased phosphorylation levels of effector molecules STAT3, AKT, ERK and S6 that are downstream of the IL-8/CXCR1/2 signaling cascade in HPAC cells. These data were in close agreement with the reduced cell migration and colony formation. Results from the present study suggested that reparixin and SCH527123 may be promising therapeutic agents for the treatment of pancreatic cancer by inhibiting the IL-8/CXCR $1 / 2$ signaling cascade.

\section{Introduction}

Pancreatic ductal adenocarcinoma (PDAC) accounts for $>90 \%$ of pancreatic cancers, and it has one of the highest mortality rates of all human cancers worldwide; most patients succumb within 1 year following diagnosis (1). It is hypothesized that of the $\sim 53,670$ people estimated to be diagnosed with this malignancy in the United States 43,090 of them will succumb in 2017 (2). Less than $15 \%$ of patients with PDAC are eligible for surgical resection, and the 5-year survival rate remains low, $20-25 \%$ (3). Owing to the absence of specific symptoms of PDAC and a lack of early detection and screening techniques, the initial diagnosis of pancreatic cancer often occurs at the advanced and metastatic stages, at which surgical resection is unfeasible (4).

Over the past several decades, most chemotherapeutic, targeted or immune-based therapeutic approaches have only yielded limited clinical outcomes (5). Since 1996, the deoxycytidine analog gemcitabine has been the most commonly used frontline therapeutic agent for patients with advanced pancreatic cancer; however, it only provides a median overall survival rate of 5.7 months (6). A previous study examined the effects of a combination therapy comprising several monotherapeutic agents, including 5-fluorouracil, leucovorin, irinotecan and oxaliplatin (collectively termed FOLFIRINOX), with gemcitabine in patients with advanced pancreatic cancer and demonstrated that FOLFIRINOX may be an effective agent; however, the median overall survival is $<1$ year (7). There has 
been an increased effort in the development of more potent treatment regimens.

The etiology of pancreatic cancer remains unknown, but may involve the dysregulation of multiple signaling effectors or cytokines, including interleukin (IL)-8, signal transducer and activator of transcription (STAT)-3, RAC- $\alpha$ serine/ threonine-protein kinase (AKT), extracellular signal-regulated kinase (ERK) and others $(8,9)$. An increasing number of studies have revealed that IL- 8 and its receptors, C-X-C chemokine receptor (CXCR)-1 and CXCR2, serve crucial roles in orchestrating the initiation and progression phases of various tumors $(10,11)$, including breast cancer $(12)$, melanoma (13), colorectal cancer (14) and pancreatic cancers (8). The CXCR1/2 signaling cascade may be inhibited by a number of strategies, such as through the administration of small-molecule inhibitors, and preclinical studies have demonstrated their promising effects on reducing the progression of human cancers $(15,16)$. Reparixin was originally developed to prevent IL-8-induced reperfusion injury (17-19), but was later revealed to be an effective small-molecule inhibitor that blocks CXCR1/2, and was used in the clinic to delay the progression and advancement of breast cancer $(20,21)$. Another small-molecule inhibitor, SCH527123, also exhibits antitumoral effects in mouse models and has been demonstrated to be effective against melanoma (22), breast cancer (23) and colorectal cancers (24). Clinical trials revealed that neither reparixin nor SCH527123 induced noticeable cytotoxicity upon treating breast cancer, ischemia-reperfusion injury (IRI) or inflammatory diseases such as asthma $(19,20,25)$. However, the efficacy of reparixin or SCH527123 on PDAC remains unknown.

The present study is the first, to the best of our knowledge, to investigate the efficacy of reparixin and SCH527123 on pancreatic cancer cell lines in vitro. The antitumoral effects of these CXCR $1 / 2$ antagonists on pancreatic cancer were determined by investigating viability, proliferation, colony formation and migration of PDAC cells treated with these agents. The results demonstrated that reparixin and SCH527123 not only blocked the mitogenic effects triggered by IL-8, but also inhibited overall cell survival, proliferation and migration. Molecular investigation further uncovered the underlying mechanism involved with the inhibition of downstream effectors, as demonstrated by the reduced phosphorylation levels of AKT, ERK, STAT3 and ribosomal protein S6 (S6). Results from the present study suggested that the CXCR1/2 antagonists, reparixin and $\mathrm{SCH}-527123$, may be novel therapeutic candidates in treating pancreatic cancer, in part by disrupting the IL-8/CXCR1/2 signaling cascade.

\section{Materials and methods}

Cell culture and reagents. Human pancreatic cancer cell lines HPAC, MIA PaCa-2, Capan-1, AsPC-1 and BxPC-3 were purchased from The American Type Culture Collection (Manassas, VA, USA). All cell lines were routinely cultured in Dulbecco's modified Eagle's medium containing $4.5 \mathrm{~g} / \mathrm{l}$ glucose, L-glutamine and sodium pyruvate (DMEM; cat. no. 10013 CV; Mediatech, Inc. A Corning Subsidiary; Manassas, VA, USA) supplemented with $10 \%$ fetal bovine serum (FBS; cat. no. S11150; Atlanta Biologicals, Flowery Branch, GA,
USA) and $1 \%$ penicillin/streptomycin (cat. no. P0781; Sigma-Aldrich; Merck KGaA, Darmstadt, Germany) in a humidified $37^{\circ} \mathrm{C}$ incubator with $5 \% \mathrm{CO}_{2}$. Cells were routinely assessed microscopically for the expected morphologies.

Reagents used in the present study were as follows: Recombinant human IL-8 (cat. no. 8921SF; Cell Signaling Technology, Inc., Danvers, MA, USA), 3-(4,5-dimethylthiazol-2-yl)-2,5-diphenyltetrazolium bromide (MTT; cat. no. M5655; Sigma-Aldrich; Merck KGaA), dimethyl sulfoxide (DMSO; cat. no. D2650; Sigma-Aldrich; Merck KGaA), N,N-dimethylformamide (DMF; cat. no. D119-4; Fisher Scientific; Thermo Fisher Scientific, Inc., Waltham, MA, USA), crystal violet (cat. no. C6158; Sigma-Aldrich; Merck KGaA), Bromodeoxyuridine (BrdU) Cell Proliferation assay kit (cat. no. 6813S; Cell Signaling Technology, Inc.) and lysis buffer (cat. no. 9803; Cell Signaling Technology, Inc.). The IL-8 powder was dissolved in sterile PBS to constitute a stock solution $(250 \mathrm{ng} / \mu \mathrm{l})$, which was stored in aliquots at $-20^{\circ} \mathrm{C}$. Reparixin was purchased from INDOFINE Chemical Co., Inc. (cat. no. 1106143; Hillsborough Township, NJ, USA), and SCH527123 was purchased from AdooQ Bioscience (cat. no. A11555; Irvine, CA, USA); both were dissolved in sterile DMSO to make a stock reagent $(20 \mathrm{mM})$ and stored in aliquots at $-20^{\circ} \mathrm{C}$.

MTT cell viability assay. AsPC-1, BxPC-3, HPAC, Capan-1 and MIA PaCa-2 cells were seeded (3,000 cells/well) in 96-well microtiter plates and cultured overnight at $37^{\circ} \mathrm{C}$ in $100 \mu$ l DMEM containing 10\% FBS. The next day, when the cells reached $\sim 20 \%$ confluency, the culture medium in each well was changed with $100 \mu 1$ DMEM $+10 \%$ FBS supplemented with various concentrations of reparixin $(10,20,40$, 60 and $80 \mu \mathrm{M})$, SCH527123 $(20,40,60,80$ and $100 \mu \mathrm{M})$ or with DMSO vehicle control under the same conditions $(\mathrm{DMEM}+10 \% \mathrm{FBS})$ at $37^{\circ} \mathrm{C}$. Following $72-\mathrm{h}$ incubation, MTT solution $(25 \mu \mathrm{l})$ was added to each well and the cells were incubated for $4 \mathrm{~h}$. Subsequently, DMF solubilization solution $(150 \mu \mathrm{l})$ was added to dissolve the formazan crystals, and the cells were incubated overnight at room temperature in a sealed moistened chamber protected from the light. Cell viability was assessed by measuring the absorbance at $595 \mathrm{~nm}$ in each well (which reflected the amount of MTT taken up by the metabolically active cells), comparing with the absorbance in the mock control wells and quantifying. Half-maximal inhibitory concentrations $\left(\mathrm{IC}_{50}\right)$ were determined using Sigma Plot 9.0 Software (Systat Software, Inc., San Jose, CA, USA).

BrdU incorporation assay for cell proliferation. The proliferative activities intrinsic to AsPC-1, Capan-1 and HPAC cells were assessed with the BrdU incorporation assay. Briefly, cells were seeded 5,000 cells/well) in 96-well plates in quadruplicate in DMEM containing 10\% FBS overnight. Subsequently, the cells were grown in the same medium but without FBS for an additional $24 \mathrm{~h}$; this serum-depleted growth condition was maintained throughout the assay. Cells were either treated with IL-8 $(10$ or $25 \mathrm{ng} / \mathrm{ml})$ alone for $24 \mathrm{~h}$ at $37^{\circ} \mathrm{C}$ or pre-treated with various concentrations of reparixin or SCH527123 (40, 60 or $80 \mu \mathrm{M})$ at $37^{\circ} \mathrm{C}$ for $4 \mathrm{~h}$ and subsequently triggered to undergo robust proliferation with the addition of IL-8 $(25 \mathrm{ng} / \mathrm{ml})$ to the 
medium for $24 \mathrm{~h}$ at $37^{\circ} \mathrm{C}$. Cells treated with DMSO were used as a control. Following $24 \mathrm{~h}$ of growth induction, the cells were further cultivated with $1 \mathrm{X} \mathrm{BrdU}$ reagent at $37^{\circ} \mathrm{C}$ for $1 \mathrm{~h}$ and the number of cells that incorporated BrdU (that is, proliferating cells actively synthesizing DNA) were quantified according to the manufacturer's protocol.

Colony formation assay. HPAC and AsPC-1 cells were seeded (2,000 cells/well) in 6-well plates and incubated overnight. Cells were subsequently incubated at $37^{\circ} \mathrm{C}$ with DMSO, or were treated with various doses of reparixin or SCH527123 (20, 40 or $60 \mu \mathrm{M})$. The culture medium with the respective treatments was changed every 3 days. After 1 week, the culture medium containing the drugs was removed and changed to fresh cell culture medium without IL- 8 inhibitors, and the medium was subsequently changed once every week without IL-8 inhibitors for another two weeks. After 2 weeks, the cells were washed twice with PBS, fixed with cold methanol for $30 \mathrm{~min}$ at $4^{\circ} \mathrm{C}$ and stained with $1 \%$ crystal violet dye (dissolved in $25 \%$ methanol) at room temperature for $1 \mathrm{~h}$. The plates were washed with distilled water and dried.

Wound-healing assay for cell migration. HPAC cells were seeded $\left(8.9 \times 10^{5}\right.$ cells/well $)$ in 6 -well plates and incubated at $37^{\circ} \mathrm{C}$ overnight. When the cells reached $100 \%$ confluence, the monolayer was scratched to create a wound using a pipette tip. The monolayer was washed with sterilized PBS, and cells were treated with DMSO, reparixin or SCH527123 at the doses of 60,80 or $100 \mu \mathrm{M}$, and incubated for $23 \mathrm{~h}$ at $37^{\circ} \mathrm{C}$; images were captured with a Nikon Eclipse TS100 microscope at 0 and $23 \mathrm{~h}$. The width of the scratch line was quantified by three independent observers and the measurements were used as an indication of cell migration. The relative woundhealing ability was calculated using the following formula: Percent wound healing $=[$ (width at $0 \mathrm{~h}-$ width at $23 \mathrm{~h}) /($ width at $0 \mathrm{~h})] \mathrm{x} 100$; the average was calculated from 5 replicates. Under this setting, the DMSO-treated control cells exhibited $100 \%$ wound-healing ability after $23 \mathrm{~h}$. The MTT assay was performed to determine if the effects of reparixin and SCH527123 on cell migration may have been affected by reduced viability. HPAC cells were seeded (20,000 cells/well) in 96 -well microtiter plates and grown to $100 \%$ confluency at $37^{\circ} \mathrm{C}$ overnight. Cells were treated with the same concentrations of reparixin and $\mathrm{SCH} 527123$ as those in the wound-healing assay, and were also incubated for $23 \mathrm{~h}$ at $37^{\circ} \mathrm{C}$. The MTT assay was conducted as aforementioned.

Western blot analysis. HPAC cells were grown to 50-60\% confluence and treated with DMSO or with reparixin or $\mathrm{SCH} 527123$ at 40,60 and $80 \mu \mathrm{M}$ for $24 \mathrm{~h}$ at $37^{\circ} \mathrm{C}$. Subsequently, the cells were harvested and lysed in ice-cold cell lysis buffer (10X; ca. no. 9803; Cell Signaling Technology, Inc.) containing protease and phosphatase inhibitors. Total protein was quantified using the Micro BCA Protein assay kit (cat. no. 23252; Thermo Fisher Scientific, Inc.) Protein lysates $(60 \mu \mathrm{g})$ were separated by $10 \%$ SDS-PAGE, and the resolved proteins were transferred to a polyvinylidene fluoride membrane (cat. no. 10600023; GE Healthcare Life Sciences, Shanghai, China). Membranes were incubated overnight at $4^{\circ} \mathrm{C}$ with primary antibodies $(1: 1,000$; all from
Cell Signaling Technology, Inc.) against phosphorylated (p)-ERK1/2 (T202/Y204; cat. no. 4695), p-STAT3 (Y705; cat. no. 9145), pan-STAT3 (cat. no. 4904), p-AKT (S473; cat. no. 4060), S6 (cat. no. 2217) and GAPDH (cat. no. 2118). The membranes were washed 3 times, 5 min each, with TBS $+0.1 \%$ Tween-20 (TBST), followed by incubation with horseradish peroxidase-conjugated goat anti-rabbit immunoglobulin G secondary antibody (1:10,000; cat. no. 7074; Cell Signaling Technology, Inc.) for $1.5 \mathrm{~h}$ at room temperature. The membranes were washed with TBST 3 times, 5 min each protein bands were visualized using SuperSignal West Femto Maximum Sensitivity Substrate (cat. no. 34096; Thermo Fisher Scientific, Inc.).

Statistical analysis. Statistical analyses were conducted using GraphPad Prism 5 software. Differences were analyzed with one-way analysis of variance followed by Tukey's post hoc test for multiple comparisons. Data are presented as the mean \pm standard error of the mean. $\mathrm{P}<0.05$ was considered to indicate a statistically significant difference.

\section{Results}

Reparixin and SCH527123 reduce cell viability. Pancreatic cancer cell lines have been shown to express IL-8 and IL-8 receptor (26-28). Owing to the variation in cell densities used in the following experiments, the higher the cell densities used, the more autocrine IL-8 were secreted to medium; therefore, higher concentrations of reparixin or SCH527123 were needed to efficiently suppress the malignant features of pancreatic cancer cells. For cell viability, the $\mathrm{IC}_{50}$ value was calculated following treatments with five different concentrations of reparixin $(10,20,40,60$ and $80 \mu \mathrm{M})$ or SCH527123 $(20,40,60,80$ or $100 \mu \mathrm{M})$ to be able to determine the optimum inhibitory effect. Inhibition of IL-8/CXCR1/2 signaling with either reparixin or SCH527123 resulted in a significant reduction in the viability of pancreatic cancer cell lines HPAC, AsPC-1, MIA PaCa-2, BxPC-3 and Capan-1 (Fig. 1A and B, respectively). The inhibitory effects were in a dose-dependent manner following 72-h treatment, and the $\mathrm{IC}_{50}$ values for reparixin were determined to be $37.66 \mu \mathrm{mol} / 1$ in HPAC, $27.45 \mu \mathrm{mol} / 1$ in AsPC-1, $30.40 \mu \mathrm{mol} / 1$ in MIA PaCa-2, $52.94 \mu \mathrm{mol} / 1$ in BxPC-3 and $34.48 \mu \mathrm{mol} / 1$ in Capan-1 cells. For cells treated with SCH527123 the $\mathrm{IC}_{50}$ values were calculated to be $53.49 \mu \mathrm{mol} / 1$ in HPAC, $48.54 \mu \mathrm{mol} /$ in AsPC-1, $14.65 \mu \mathrm{mol} / 1$ in MIA PaCa-2, $42.14 \mu \mathrm{mol} / 1$ in BxPC-3 and $15.63 \mu \mathrm{mol} / 1$ in Capan-1 cells.

Reparixin and SCH527123 suppress IL-8-stimulated cell proliferation. As the inhibition of CXCR $1 / 2$ signaling was demonstrated to reduce PDAC cell viability (Fig. 1), and that this signaling cascade was previously reported to regulate cell proliferation (16), the effects of reparixin and SCH527123 on the proliferative activities associated with pancreatic cancer cells was examined by the BrdU incorporation assay. As demonstrated in Fig. 2A, IL-8 treatment stimulated Capan-1, AsPC-1 and HPAC cell proliferation in a dose-dependent manner; Subsequently, cells were treated with DMSO or with either reparixin or SCH527123 at various concentrations for $4 \mathrm{~h}$, followed by treatment with IL-8 $(25 \mathrm{ng} / \mathrm{ml})$ for $24 \mathrm{~h}$. The 

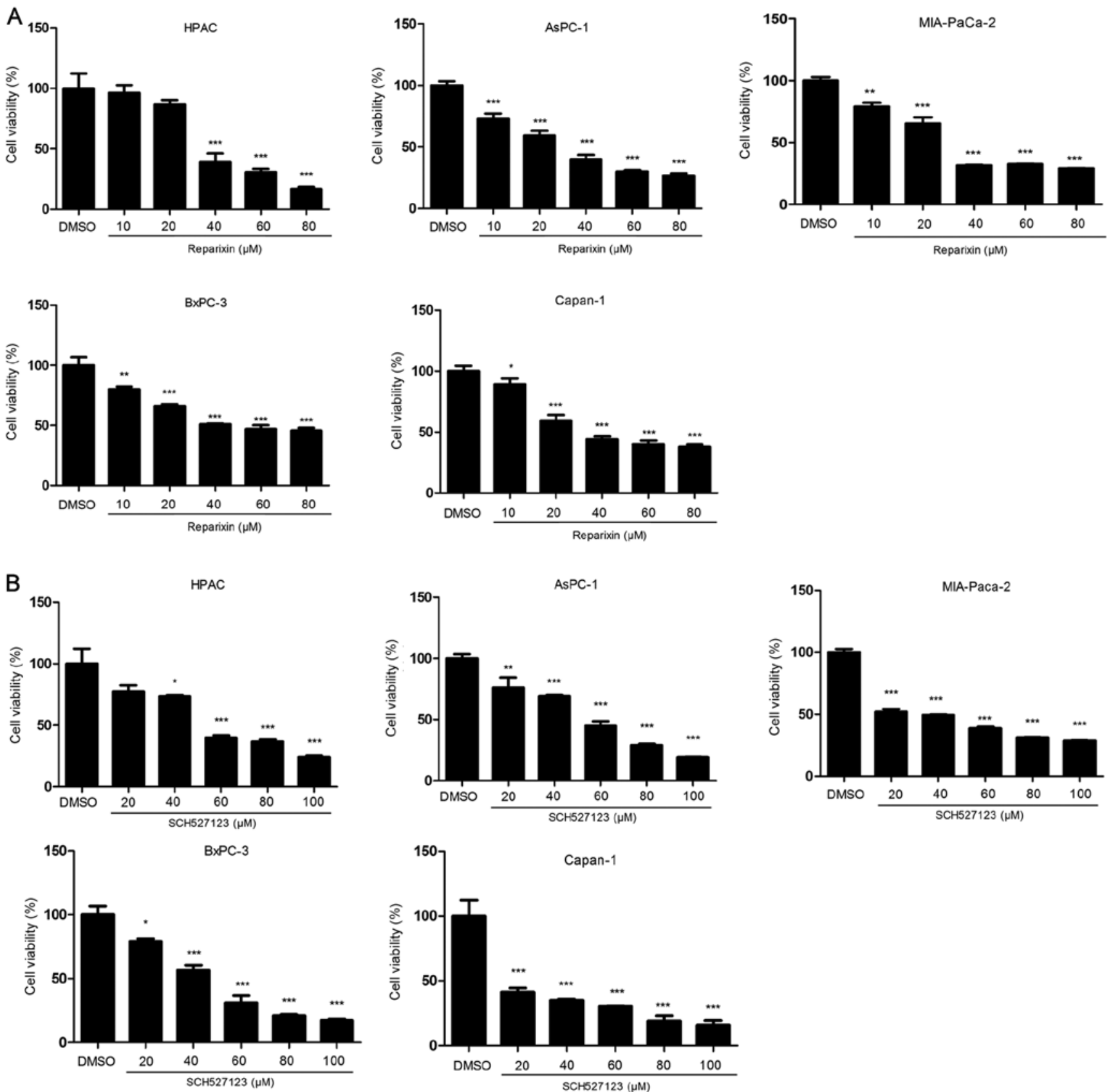

Figure 1. Cell viability of human pancreatic cancer cells treated with various concentrations of either reparixin or SCH527123. HPAC, AsPC-1, MIA-Paca-2, BxPC-3 and Capan-1 cells were seeded at 3,000 cells/well in 96-well plates and incubated with various concentrations of (A) reparixin or (B) SCH527123 for 72 h. Cell viability was measured by MTT assay. ${ }^{*} \mathrm{P}<0.05,{ }^{* * *} \mathrm{P}<0.01$ and ${ }^{* * *} \mathrm{P}<0.001$ vs. DMSO. DMSO, dimethyl sulfoxide.

inhibitory effects on the drug-treated cells were assessed by BrdU incorporation assays; IL-8-induced cell proliferation was reduced in cells treated with reparixin (Fig. 2B) or with SCH527123 (Fig. 2C) in a dose-dependent manner.

Reparixin and SCH527123 reduce the ability of PDAC cell lines to grow and form colonies. The effects of reparixin and SCH527123 on the intrinsic ability of pancreatic cancer cells to grow and form colonies were examined. AsPC-1 and HPAC cells, seeded in six-well plates, were treated with either DMSO or with either inhibitor, reparixin or SCH527123. The colonies grew in the DMSO control treated cells, 3 week, and the plates were stained and images of colony growth were captured (Fig. 3). Consistent with the results from viability and proliferation assays aforementioned, the inhibition of CXCR1/2 by reparixin or SCH527123 treatment reduced the colony-forming ability of PDAC cell lines.

Reparixin and SCH527123 inhibit cell migration. Previous studies have indicated that CXCR1/2 signaling was crucial for cell migration, which is important for tumor invasion and metastasis $(29,30)$. Therefore, the present study examined the effects of CXCR1/2 signaling inhibition on the migratory ability of HPAC cells (Fig. 4). Following treatment with either reparixin or SCH527123, cell migratory ability was examined by wound healing assays. The results demonstrated that the 
A

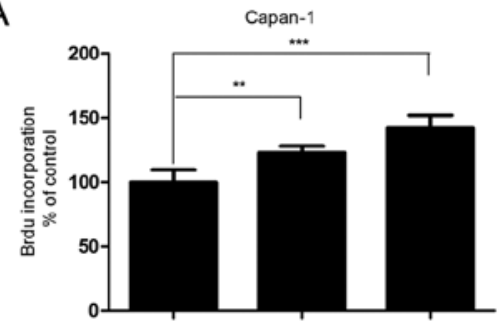

IL-8 $8(\mathrm{ng} / \mathrm{m})$

10

25

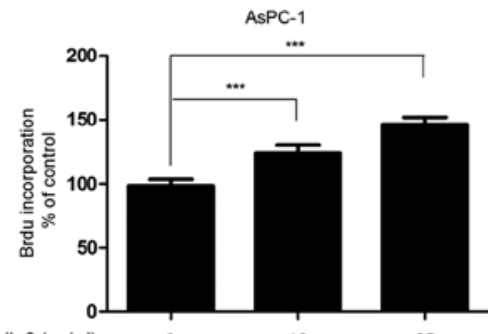

IL-8 (ng/ml) $\quad 0 \quad 10 \quad 25$

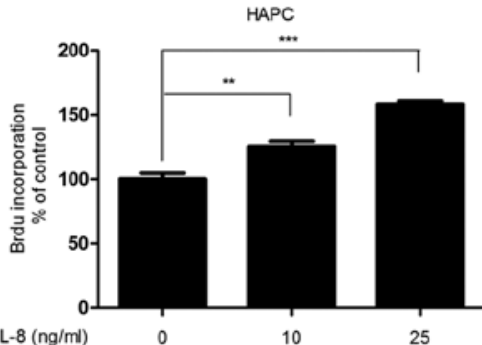

B
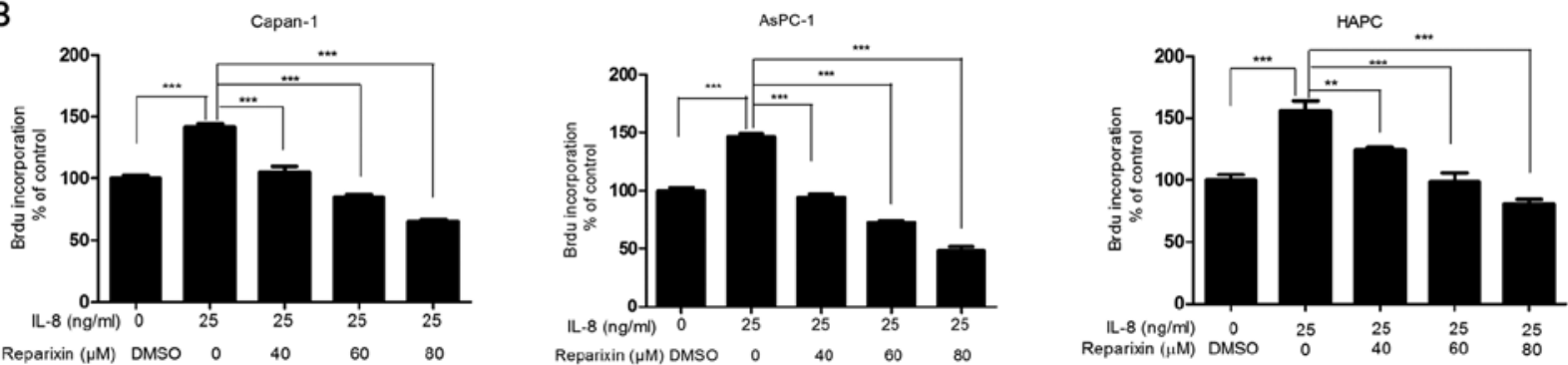

C
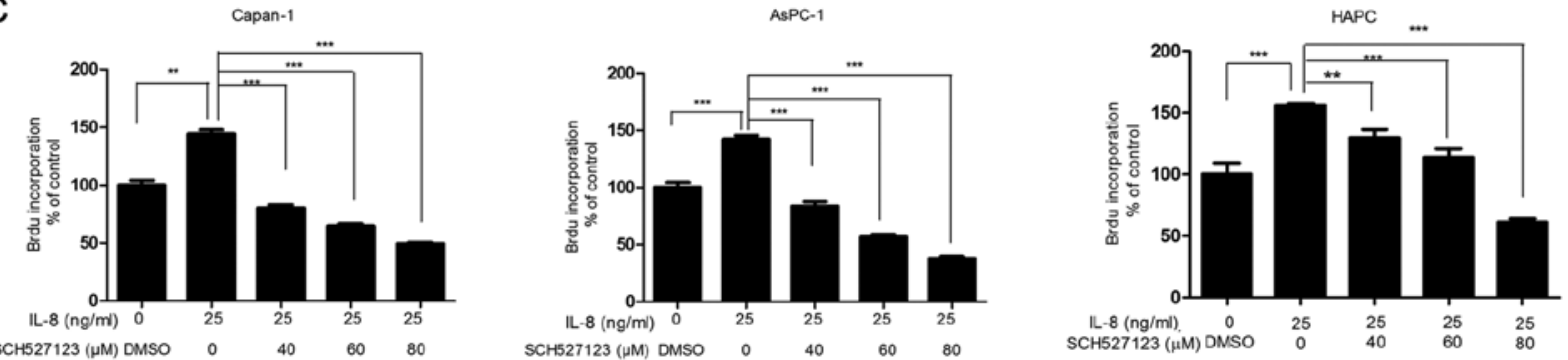

Figure 2. IL-8-induced human pancreatic cancer cell proliferation is inhibited by reparixin or SCH527123. Capan-1, AsPC-1 and HPAC were seeded at a density of 5,000 cells/well at 96-well plates. They were serum-depleted for $24 \mathrm{~h}$ and subsequently treated with various concentrations of IL-8 for $24 \mathrm{~h}$. BrdU was added for $1 \mathrm{~h}$ and the absorbance, indicative of DNA proliferation, was read at $450 \mathrm{~nm}$. (A) Cell proliferation was induced by IL- 8 in dose-dependent manner. (B and C) To test the effects inhibitors on cell proliferation, cells were pretreated with various concentrations of either reparixin or SCH527123, or with DMSO for $4 \mathrm{~h}$ and subsequently triggered to undergo robust proliferation with the addition of IL- 8 for $24 \mathrm{~h}$ followed by BrdU incorporation assay. ${ }^{*} \mathrm{P}<0.05$, ${ }^{* *} \mathrm{P}<0.01$ and ${ }^{* * *} \mathrm{P}<0.001$ vs. DMSO. BrdU, bromodeoxyuridine; DMSO, dimethyl sulfoxide; IL, interleukin.

A
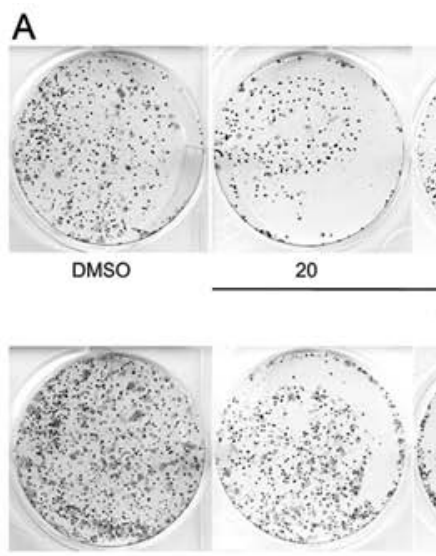

DMSO

AsPC-1
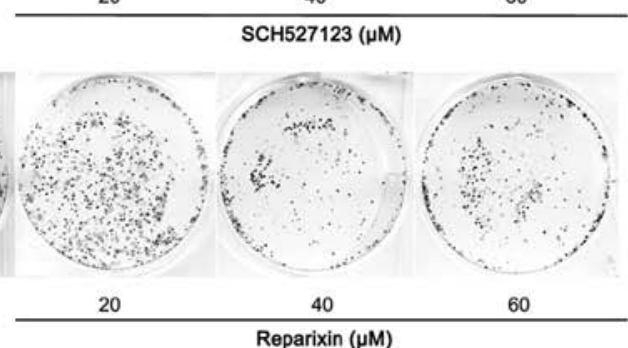

B

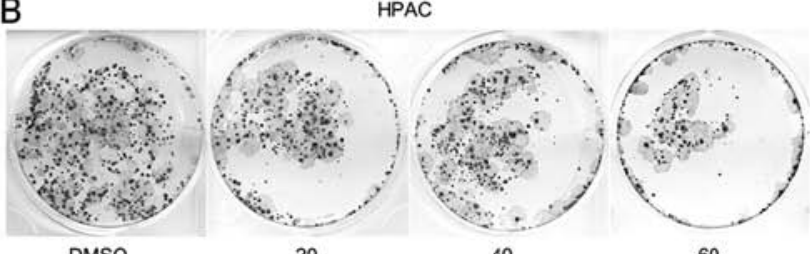

20

40

$\mathrm{SCH} 527123(\mu \mathrm{M})$

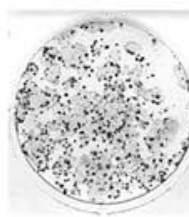

DMSO

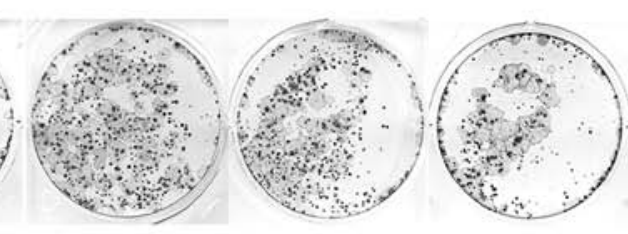

20

40

Reparixin $(\mu \mathrm{M})$

Figure 3. Colony-forming ability of pancreatic cancer cells is significantly inhibited by reparixin or SCH527123 treatment. (A) AsPC-1 and (B) HPAC pancreatic cancer cells were seeded at 2,000 cells/well in 6-well plates and incubated for 1 week with various concentrations of reparixin or SCH527123, as indicated, and subsequently fixed and stained to assess colony formation. DMSO, dimethyl sulfoxide.

migratory potential was reduced in cells treated with either reparixin (Fig. 4A and B) or SCH527123 (Fig. 4D and E) in a dose-dependent manner, compared with the control cells treated with DMSO. Subsequent MTT assay experiments indicated that the effects of CXCR1/2 inhibition on migration were not a result of reduced viability (Fig. $4 \mathrm{C}$ and F). These 

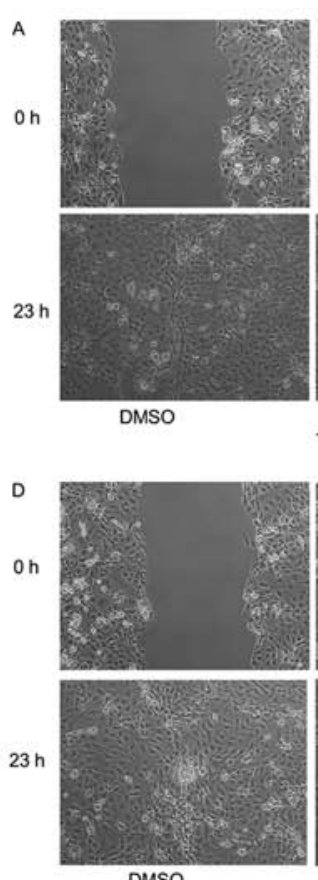

DMSO

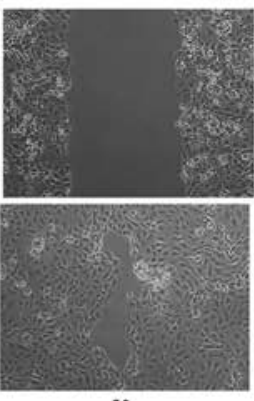

60

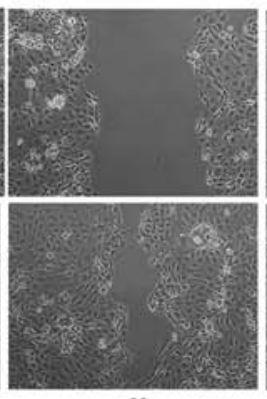

80

Reparixin $(\mu \mathrm{M})$

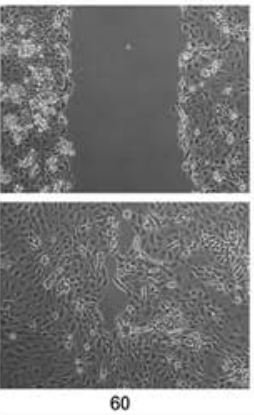

60

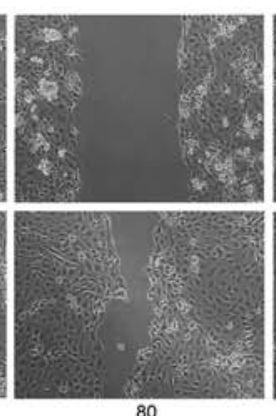

80

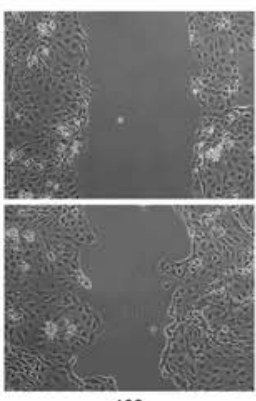

100
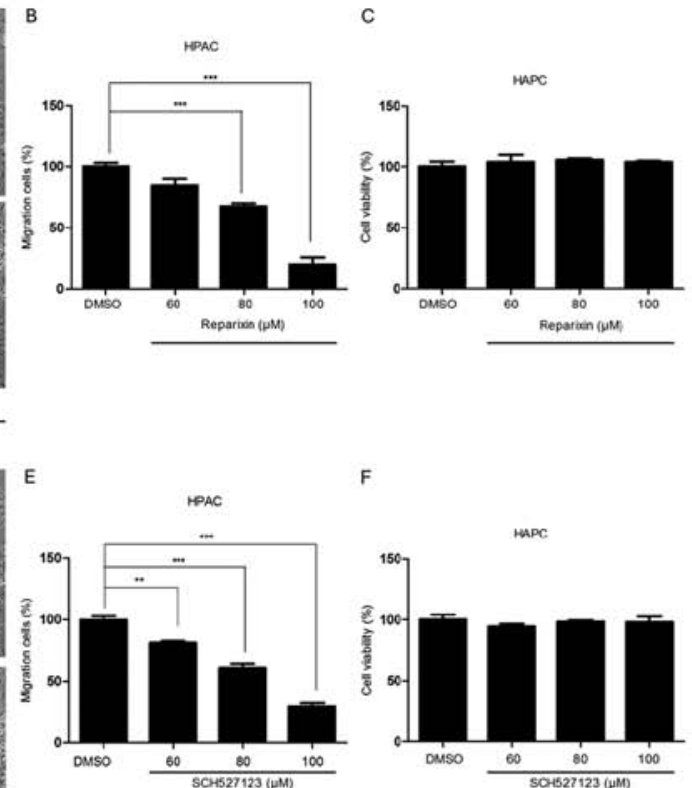

Figure 4. Reparixin and SCH527123 treatment inhibit cell migration in HPAC cells. (A) A wound-healing assay, indicative of migratory ability, was conducted by scratching a line in the cells when HPAC cells grew into confluence in monolayer. The cells were subsequently treated with different concentrations of reparixin for $23 \mathrm{~h}$. Magnification, x100 (B) Images were captured and the width of the scratched lines were quantified; the wound healing in the DMSO control treated cells was set as $100 \%$ to indicate and compare wound healing/migratory abilities; migratory potential was inhibited in cells treated with either reparixin in a dose-dependent manner. (C) The MTT assay was also performed to examine whether reparixin treatment reduced the viability of cells in the woundhealing assay. The drug concentrations and the incubation time were the same as those applied in the wound-healing assay. (D-F) The effects of SCH527123 treatment on cell migration were also (D) examined by wound-healing assay and (E) quantified. (F) Similarly, the MTT assay was conducted to determine any effects of SCH527123 on cell viability in the wound-healing assay. ${ }^{*} \mathrm{P}<0.05,{ }^{* *} \mathrm{P}<0.01$ and ${ }^{* * *} \mathrm{P}<0.001$. DMSO, dimethyl sulfoxide.
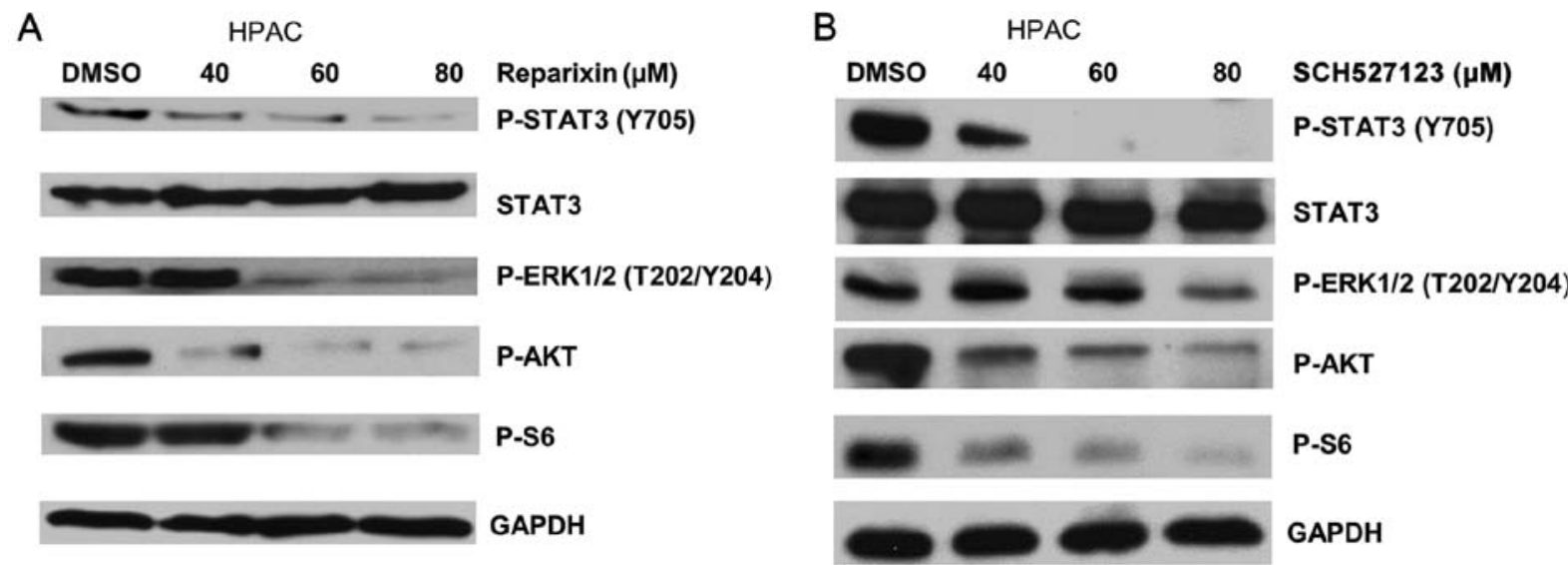

Figure 5. Reparixin and SCH527123 inhibit the phosphorylation of STAT3, ERK, AKT and S6 in HPAC cells. (A and B) HPAC pancreatic cancer cells were treated with either (A) reparixin or (B) SCH527123, or with DMSO as a control. The cells were harvested after $24 \mathrm{~h}$ and changes in the phosphorylation levels of STAT3 (Y705), AKT (S473), ERK (T202/Y204) and ribosomal S6 were examined by western blotting. AKT, RAC- $\alpha$ serine/threonine-protein kinase; DMSO, dimethyl sulfoxide; ERK, extracellular signal-regulated kinase; p, phosphorylated; S6, ribosomal protein S6; STAT3, signal transducerand activator of transcription 3.

data demonstrated that inhibition of CXCR1/2 by reparixin or SCH527123 may block the migratory ability of pancreatic cell lines.

Inhibition of $C X C R 1 / 2$ signaling pathway reduces activation of downstream effectors $p$-AKT, $p$-ERK, $p$-STAT3 and $p$-S6. Previous reports have indicated that IL- 8 advances tumor progression by activating downstream effectors, including phosphatidylinositol 3-kinase (PI3K)/AKT (31), Ras/mitogen-activated protein kinase (MAPK) (32-34), Janus kinase (JAK)/STAT3 $(35,36)$ and S6 (37) pathways. To determine the underlying mechanism of how reparixin and SCH527123 are able to reduce the overall malignant features in pancreatic cancer cells, the present study investigated whether these inhibitors disrupted the activation of downstream effectors that are regulated by IL-8/CXCR1/2. 
Western blot analysis was used to examine the changes in phosphorylation status of the targeted effectors, which was indicative of the activation status of the effectors. The results demonstrated that HPAC cells treated with either reparixin or SCH527123 exhibited reduced phosphorylation levels of ERK and AKT, with the greatest reduction observed in cells treated with $80 \mu \mathrm{M}$ SCH527123 (Fig. 5A and B, respectively). Similarly, the phosphorylation of S6, which is known to regulate cell growth and proliferation through the selective translation of particular classes of mRNA (38), was inhibited in a dose-dependent manner by both inhibitors, with SCH527123 appearing to be more potent compared with reparixin (Fig. 5).

Neither inhibitor treatment affected the overall expression of total STAT3 proteins (Fig. 5). However, these inhibitors remarkably impaired STAT3 phosphorylation at Y705 in a dose-dependent manner (Fig. 5). These results suggested for the first time, to the best of our knowledge, that reparixin and SCH527123 impaired STAT3 activation by inhibiting its phosphorylation rather than by suppressing overall protein expression. The present study results demonstrated that reparixin and SCH527123 function to suppress protein phosphorylation, thus inhibiting the activation of AKT, ERK, S6 and STAT3 in the HPAC cancer cell line, in a dose-dependent manner.

\section{Discussion}

The present study demonstrated that inhibition of the CXCR1/2 pathway by reparixin and SCH527123 treatment reduced pancreatic cancer neoplastic features, such as cell viability, proliferation, colony formation and migratory potential in PDAC cell lines. Molecular investigations revealed that the antagonists also suppressed the phosphorylation that led to activation of downstream targets STAT3, AKT, ERK and ribosomal S6.

Consistent with previous studies conducted on melanoma and colon cancer $(13,14)$, the present study results demonstrated that IL-8 stimulation accelerated PDAC cell proliferation. Treatments with the inhibitory agents reparixin and SCH527123, which block the IL-8/CXCR1/2 signaling pathway, were able to reduce the aforementioned malignant phenotypes. The tumor-promoting effects of IL-8 not only stimulated growth, but also promoted cancer cell migration and invasion in a colon cancer model (14). The migratory ability that is intrinsic to pancreatic cancer cells, and which preludes tumor metastasis, was revealed to be inhibited by reparixin and SCH527123 in the present study. A previous study reported that IL-8 exposure enhanced pancreatic cancer cell invasion and that this effect was reversed by treatment with an antagonizing CXCR1-specific antibody (39). Similarly, an in vivo study using animal models further confirmed the cancer inhibitory effects exerted by reparixin and SCH527123 treatment $(15,20-23)$. A pre-clinical study by Brandolini et al demonstrated that reparixin was able to target breast cancer cells in xenograft models and led to prominent tumor regression along with reduced metastasis (15).

Notably, pre-clinical trials using reparixin presented negligible adverse effects and no obvious cytotoxicity was observed. For example, in a double-blinded, placebocontrolled pilot study designed to evaluate the safety and efficacy of reparixin for treating IRI and inflammation in patients undergoing coronary artery bypass grafting (CABG), no apparent side-effects were noted, which indicated that reparixin treatment in patients with $\mathrm{CABG}$ appeared to be safe and well tolerated (19). Similarly, SCH527123 was revealed to be safe and well tolerated in otherwise healthy individuals suffering from severe asthma $(25,40)$.

The safety and efficacy of reparixin to treat cancer have also been evaluated. The outcomes from a phase Ib clinical trial that examined the dose and safety of oral reparixin treatment combined with paclitaxel in women with metastatic breast cancer revealed that the oral administration of reparixin three times per day appeared to be safe and tolerable (20). These data provided promising support for the use of reparixin as an anticancer drug. Results from the present study demonstrated that reparixin inhibited pancreatic cancer cell proliferation, colony formation, migration and cell viability. These results, in conjunction with the safety and efficacy determined by previous studies, indicated the potential benefit of administering reparixin as a novel therapeutic agent for treating pancreatic cancer. Similarly, the inhibitor SCH527123 was used in a pre-clinical xenograft model of colorectal cancer and was reported to inhibit tumor growth (24). Co-treatment of SCH527123 with oxaliplatin resulted in reductions in cell proliferation, tumor growth and angiogenesis that were greater than treatment with either agent alone (24). Taken together, these results indicated that SCH527123 may be a novel targeted therapeutic agent that may be used to treat pancreatic cancer.

To better understand the mechanism of action of these two inhibitor compounds, the expression levels of the main effectors downstream of the IL-8/CXCR $1 / 2$ pathway were examined in the present study. Previous studies reported that PI3K was a main target of IL-8 signaling, and that activated PI3K pathway resulted in increased phosphorylation of its substrate AKT (31). The phosphorylation of AKT initiated by IL-8 signaling has been examined in a number of cancer cell lines, which resulted in modulations of cell survival, cell migration and angiogenesis $(41,42)$. The present study demonstrated that treatment with either reparixin or SCH527123 notably reduced the phosphorylation levels of AKT. These data suggested that reparixin or SCH527123 may be able to inhibit pancreatic cancer cell viability, proliferation and migration through the inhibition of AKT signaling, which is in agreement with a previous study (21).

A number of previous studies using cancer cells have also reported that IL-8 regulates cell survival, cell proliferation and invasion through the MAPK signaling pathway and the subsequent phosphorylation of the downstream effectors ERK1/2 $(33,37,43)$, which was previously reported to serve an important role in enhancing oncogenic behavior and increasing the invasive potential of melanoma cells $(32,34)$. Results from the present study demonstrated that HPAC cells treated with either reparixin or SCH527123 exhibited a reduction in the level of ERK1/2 phosphorylation. These data suggested a role for the ERK pathway in enhancing survival, proliferation and invasion of pancreatic cancer cells.

A previous study has also revealed that functional inactivation of STAT3 led to significant inhibition of pancreatic cancer cell proliferation in vitro and led to reduced tumor growth in vivo, and activated STAT3 contributed to the 
malignant phenotype of human pancreatic cancer in part by promoting cellular proliferation through accelerated G1/S-phase progression (44). STAT3 activation can be stimulated by IL- 8 signaling through CXCR2, as demonstrated by a previous study that used an IL-8 neutralizing antibody to downregulate S727-phosphorylation of STAT3 in hepatoma cells (36). Results from the present study indicated that reparixin and SCH527123 may reduce cell proliferation and colony formation by inhibiting STAT3 phosphorylation, rather than by suppressing its overall protein expression level. These data demonstrated a potentially crucial role of the STAT3 pathway in IL-8-CXCR $1 / 2$ signaling and in stimulating pancreatic cancer cell growth.

S6 was previously reported to modulate cellular metabolic events, including protein and lipid synthesis, transcription, translation, cell metabolism and cell growth (45). IL-8 was revealed to induce the phosphorylation of ribosomal S6 kinase, which results in the subsequent phosphorylation and activation of S6 (34). Results from the present study demonstrated that reparixin and SCH527123 suppressed the expression of p-S6 in a dose-dependent manner, by blocking the signaling transduction conveyed from the IL-8/CXCR $1 / 2$ pathway.

In conclusion, the present study demonstrated that the CXCR1/2 antagonists, reparixin and SCH527123, exhibited antitumor activities in PDAC cell lines. The present study was the first, to the best of our knowledge, to demonstrate that the antitumor activity of reparixin and SCH527123 on cancer cell growth, motility and migration may function through the STAT3/AKT/ERK/S6 signaling pathways. Based on these results, reparixin and SCH527123 may be promising therapeutic candidates for treating human pancreatic cancer. Future in vivo investigations of the effects of these drugs on tumor-bearing laboratory animals should be conducted prior to clinical trials in patients with PDAC.

\section{Acknowledgements}

We wish to thank Dr Rich Eckert at the Department of Biochemistry and Molecular Biology at The University of Maryland (Baltimore, MD, USA) for providing the microscope used for cell migration analysis.

\section{Funding}

This study was supported by The University of Maryland School of Medicine and the Comprehensive Cancer Center start-up fund.

\section{Availability of data and materials}

All data generated and analyzed during this study are included in this published article.

\section{Authors' contributions}

JL conceived and designed the experiments, and contributed reagents, materials and analytical tools. SF and XC performed the experiments. SF, HJL and JL analyzed the data and wrote the paper.

\section{Ethics approval and consent to participate}

Not applicable.

\section{Consent for publication}

Not applicable.

\section{Competing interests}

All authors declared that they have no competing interests with regard to this work.

\section{References}

1. Vincent A, Herman J, Schulick R, Hruban RH and Goggins M: Pancreatic cancer. Lancet 378: 607-620, 2011.

2. Siegel RL, Miller KD and Jemal A: Cancer Statistics, 2017. CA Cancer J Clin 67: 7-30, 2017.

3. Stathis A and Moore MJ: Advanced pancreatic carcinoma: Current treatment and future challenges. Nat Rev Clin Oncol 7: 163-172, 2010.

4. Edwards BK, Brown ML, Wingo PA, Howe HL, Ward E, Ries LA, Schrag D, Jamison PM, Jemal A, Wu XC, et al: Annual report to the nation on the status of cancer, 1975-2002, featuring population-based trends in cancer treatment. J Natl Cancer Inst 97: 1407-1427, 2005.

5. Riall TS, Nealon WH, Goodwin JS, Zhang D, Kuo YF, Townsend CM Jr and Freeman JL: Pancreatic cancer in the general population: Improvements in survival over the last decade. J Gastrointest Surg 10: 1212-1223, discussion 1223-4, 2006.

6. Moore MJ, Goldstein D, Hamm J, Figer A, Hecht JR, Gallinger S, Au HJ, Murawa P, Walde D, Wolff RA, et al; National Cancer Institute of Canada Clinical Trials Group: Erlotinib plus gemcitabine compared with gemcitabine alone in patients with advanced pancreatic cancer: A phase III trial of the National Cancer Institute of Canada Clinical Trials Group. J Clin Oncol 25: 1960-1966, 2007.

7. Conroy T, Desseigne F, Ychou M, Bouché O, Guimbaud R, Bécouarn Y, Adenis A, Raoul JL, Gourgou-Bourgade S, de la Fouchardière $\mathrm{C}$, et al; Groupe Tumeurs Digestives of Unicancer; PRODIGE Intergroup: FOLFIRINOX versus gemcitabine for metastatic pancreatic cancer. N Engl J Med 364: 1817-1825, 2011.

8. Hertzer KM, Donald GW and Hines OJ: CXCR2: A target for pancreatic cancer treatment? Expert Opin Ther Targets 17: 667-680, 2013.

9. Pham NA, Schwock J, Iakovlev V, Pond G, Hedley DW and Tsao MS: Immunohistochemical analysis of changes in signaling pathway activation downstream of growth factor receptors in pancreatic duct cell carcinogenesis. BMC Cancer 8: 43, 2008.

10. Holmes WE, Lee J, Kuang WJ, Rice GC and Wood WI: Structure and functional expression of a human interleukin-8 receptor. Science 253: 1278-1280, 1991.

11. Murphy PM and Tiffany HL: Cloning of complementary DNA encoding a functional human interleukin-8 receptor. Science 253: 1280-1283, 1991.

12. Singh JK, Simões BM, Howell SJ, Farnie G and Clarke RB: Recent advances reveal IL-8 signaling as a potential key to targeting breast cancer stem cells. Breast Cancer Res 15: 210, 2013.

13. Gabellini C, Trisciuoglio D, Desideri M, Candiloro A, Ragazzoni Y, Orlandi A, Zupi G and Del Bufalo D: Functional activity of CXCL8 receptors, CXCR1 and CXCR2, on human malignant melanoma progression. Eur J Cancer 45: 2618-2627, 2009.

14. Shen T, Yang Z, Cheng X, Xiao Y, Yu K, Cai X, Xia C and Li Y: CXCL8 induces epithelial-mesenchymal transition in colon cancer cells via the PI3K/Akt/NF- $x \mathrm{~B}$ signaling pathway. Oncol Rep 37: 2095-2100, 2017.

15. Brandolini L, Cristiano L, Fidoamore A, De Pizzol M, Di Giacomo E, Florio TM, Confalone G, Galante A, Cinque B, Benedetti E, et al: Targeting CXCR1 on breast cancer stem cells: Signaling pathways and clinical application modelling. Oncotarget 6: 43375-43394, 2015. 
16. Liu Q, Li A, Tian Y, Wu JD, Liu Y, Li T, Chen Y, Han X and Wu K: The CXCL8-CXCR1/2 pathways in cancer. Cytokine Growth Factor Rev 31: 61-71, 2016.

17. Chapman RW, Minnicozzi M, Celly CS, Phillips JE, Kung TT, Hipkin RW, Fan X, Rindgen D, Deno G, Bond R, et al: A novel, orally active CXCR1/2 receptor antagonist, Sch527123, inhibits neutrophil recruitment, mucus production, and goblet cell hyperplasia in animal models of pulmonary inflammation. J Pharmacol Exp Ther 322: 486-493, 2007.

18. Bertini R, Allegretti M, Bizzarri C, Moriconi A, Locati M, Zampella G, Cervellera MN, Di Cioccio V, Cesta MC, Galliera E, et al: Noncompetitive allosteric inhibitors of the inflammatory chemokine receptors CXCR1 and CXCR2: Prevention of reperfusion injury. Proc Natl Acad Sci USA 101: 11791-11796, 2004.

19. Opfermann P, Derhaschnig U, Felli A, Wenisch J, Santer D, Zuckermann A, Dworschak M, Jilma B and Steinlechner B: A pilot study on reparixin, a CXCR1/2 antagonist, to assess safety and efficacy in attenuating ischaemia-reperfusion injury and inflammation after on-pump coronary artery bypass graft surgery. Clin Exp Immunol 180: 131-142, 2015.

20. Schott AF, Goldstein LJ, Cristofanilli M, Ruffini PA, McCanna S, Reuben JM, Perez RP, Kato G and Wicha M: Phase ib pilot study to evaluate reparixin in combination with weekly paclitaxel in patients with HER-2-Negative metastatic breast cancer. Clin Cancer Res 23: 5358-5365, 2017.

21. Ginestier C, Liu S, Diebel ME, Korkaya H, Luo M, Brown M, Wicinski J, Cabaud O, Charafe-Jauffret E, Birnbaum D, et al: CXCR1 blockade selectively targets human breast cancer stem cells in vitro and in xenografts. J Clin Invest 120: 485-497, 2010

22. Singh S, Sadanandam A, Nannuru KC, Varney ML, Mayer-Ezell R, Bond R and Singh RK: Small-molecule antagonists for CXCR2 and CXCR1 inhibit human melanoma growth by decreasing tumor cell proliferation, survival, and angiogenesis. Clin Cancer Res 15: 2380-2386, 2009.

23. Wang Y, Liu J, Jiang Q, Deng J, Xu F, Chen X, Cheng F, Zhang Y, Yao Y, Xia Z, et al: Human adipose-derived mesenchymal stem cell-secreted CXCL1 and CXCL8 facilitate breast tumor growth by promoting angiogenesis. Stem Cells 35: 2060-2070, 2017.

24. Ning Y, Labonte MJ, Zhang W, Bohanes PO, Gerger A, Yang D, Benhaim L, Paez D, Rosenberg DO, Nagulapalli Venkata KC, et al: The CXCR2 antagonist, SCH-527123, shows antitumor activity and sensitizes cells to oxaliplatin in preclinical colon cancer models. Mol Cancer Ther 11: 1353-1364, 2012.

25. Nair P, Gaga M, Zervas E, Alagha K, Hargreave FE, O'Byrne PM, Stryszak P, Gann L, Sadeh J and Chanez P; Study Investigators: Safety and efficacy of a CXCR2 antagonist in patients with severe asthma and sputum neutrophils: A randomized, placebocontrolled clinical trial. Clin Exp Allergy 42: 1097-1103, 2012.

26. Kuwada Y, Sasaki T, Morinaka K, Kitadai Y, Mukaida N and Chayama K: Potential involvement of IL-8 and its receptors in the invasiveness of pancreatic cancer cells. Int J Oncol 22 : 765-771, 2003

27. TakamoriH,Oades ZG,Hoch OC,BurgerMand Schraufstatter IU: Autocrine growth effect of IL-8 and GROalpha on a human pancreatic cancer cell line, Capan-1. Pancreas 21: 52-56, 2000.

28. Miyamoto M, Shimizu Y, Okada K, Kashii Y, Higuchi K and Watanabe A: Effect of interleukin-8 on production of tumorassociated substances and autocrine growth of human liver and pancreatic cancer cells. Cancer Immunol Immunother 47: 47-57, 1998.

29. Li Z, Wang Y, Dong S, Ge C, Xiao Y, Li R, Ma X, Xue Y, Zhang Q, Lv J, et al: Association of CXCR1 and 2 expressions with gastric cancer metastasis in ex vivo and tumor cell invasion in vitro. Cytokine 69: 6-13, 2014.
30. Jayatilaka H, Tyle P, Chen JJ, Kwak M, Ju J, Kim HJ, Lee JSH, Wu PH, Gilkes DM, Fan R, et al: Synergistic IL-6 and IL-8 paracrine signalling pathway infers a strategy to inhibit tumour cell migration. Nat Commun 8: 15584, 2017.

31. Knall C, Worthen GS and Johnson GL: Interleukin 8-stimulated phosphatidylinositol-3-kinase activity regulates the migration of human neutrophils independent of extracellular signal-regulated kinase and p38 mitogen-activated protein kinases. Proc Natl Acad Sci USA 94: 3052-3057, 1997.

32. Smalley KS: A pivotal role for ERK in the oncogenic behaviour of malignant melanoma? Int J Cancer 104: 527-532, 2003.

33. Venkatakrishnan G, Salgia R and Groopman JE: Chemokine receptors CXCR-1/2 activate mitogen-activated protein kinase via the epidermal growth factor receptor in ovarian cancer cells. J Biol Chem 275: 6868-6875, 2000.

34. Zhuang L, Lee CS, Scolyer RA, McCarthy SW, Palmer AA, Zhang XD, Thompson JF, Bron LP and Hersey P: Activation of the extracellular signal regulated kinase (ERK) pathway in human melanoma. J Clin Pathol 58: 1163-1169, 2005.

35. Burger M, Hartmann T, Burger JA and Schraufstatter I: KSHV-GPCR and CXCR2 transforming capacity and angiogenic responses are mediated through a JAK2-STAT3-dependent pathway. Oncogene 24: 2067-2075, 2005.

36. Zhu B, Lin N, Zhang M, Zhu Y, Cheng H, Chen S, Ling Y, Pan W and Xu R: Activated hepatic stellate cells promote angiogenesis via interleukin-8 in hepatocellular carcinoma. J Transl Med 13: 365, 2015.

37. MacManus CF, Pettigrew J, Seaton A, Wilson C, Maxwell PJ, Berlingeri S, Purcell C, McGurk M, Johnston PG and Waugh DJ: Interleukin-8 signaling promotes translational regulation of cyclin D in androgen-independent prostate cancer cells. Mol Cancer Res 5: 737-748, 2007.

38. Nandagopal N and Roux PP: Regulation of global and specific mRNA translation by the mTOR signaling pathway. Transl Austin 3: e983402, 2015.

39. Chen L, Fan J, Chen H, Meng Z, Chen Z, Wang P and Liu L: The IL-8/CXCR1 axis is associated with cancer stem cell-like properties and correlates with clinical prognosis in human pancreatic cancer cases. Sci Rep 4: 5911, 2014.

40. Holz O, Khalilieh S, Ludwig-Sengpiel A, Watz H, Stryszak P, Soni P, Tsai M, Sadeh J and Magnussen H: SCH527123, a novel CXCR2 antagonist, inhibits ozone-induced neutrophilia in healthy subjects. Eur Respir J 35: 564-570, 2010.

41. Bi LK, Zhou N, Liu C, Lu FD, Lin TX, Xuan XJ, Jiang C, Han JL, Huang H, Zhang CX, et al: Kidney cancer cells secrete IL-8 to activate Akt and promote migration of mesenchymal stem cells. Urol Oncol 32: 607-612, 2014.

42. Li XJ, Peng LX, Shao JY, Lu WH, Zhang JX, Chen S, Chen ZY, Xiang YQ, Bao YN, Zheng FJ, et al: As an independent unfavorable prognostic factor, IL-8 promotes metastasis of nasopharyngeal carcinoma through induction of epithelialmesenchymal transition and activation of AKT signaling. Carcinogenesis 33: 1302-1309, 2012.

43. Luppi F, Longo AM, de Boer WI, Rabe KF and Hiemstra PS: Interleukin-8 stimulates cell proliferation in non-small cell lung cancer through epidermal growth factor receptor transactivation. Lung Cancer 56: 25-33, 2007.

44. Scholz A, Heinze S, Detjen KM, Peters M, Welzel M, Hauff P, Schirner M, Wiedenmann B and Rosewicz S: Activated signal transducer and activator of transcription 3 (STAT3) supports the malignant phenotype of human pancreatic cancer. Gastroenterology 125: 891-905, 2003.

45. Magnuson B, Ekim B and Fingar DC: Regulation and function of ribosomal protein S6 kinase (S6K) within mTOR signalling networks. Biochem J 441: 1-21, 2012. 